\title{
13 Resource use in a post-fossil green Germany
}

\author{
Monika Dittrich, Karl Schoer, Jens Günther, \\ Philip Nuss, and Harry Lehmann
}

\section{Introduction}

Human life requires materials. Our current human experience is that the amount of used materials increases with the level of wealth. According to IRP (2017a) estimates, there could be a doubling of the materials that would be extracted globally by 2050 , if significant changes in our way of production and consumption. The extraction and processing of materials are linked to environmental harnessing and damage, such as climate change, loss of soil fertility and biodiversity, water stress, among others. Therefore, it can also be expected that the environmental impact will at least double as well. To mitigate climate change, the fossil-based economies have to change towards a post-fossil, circular, sustainable economy. This raises the question of how many materials are required in a post-fossil world? Likewise, it is of interest to know how many and what kind of materials are necessary for such an economic transformation?

Chapter 12 of this volume has presented different transformation pathways towards a 95\% Greenhouse gas emission saving in 2050:

- GreenEe as an energy-efficient pathway.

- GreenLate with a less ambitious and late transformation.

- GreenMe with high efforts in material efficiency.

- GreenLife with high lifestyle changes.

- GreenSupreme, which combines the best of material efficiency and lifestyle changes.

For all of the five pathways, primary resource consumption is declining as demonstrated in Chapter 12. By analysing the material used in more detail, this chapter goes a step further and ponders important questions: What are the relevant strategies and measures that lead to a reduction of primary material demand? How many secondary materials are used? What is the future demand for raw materials? Will there be enough raw materials available for Germany? This chapter answers these questions by partly using selected raw materials as examples. 


\section{Strategies and measures to reduce resource use in green Germany}

All green scenarios include strategies with respect to material efficiency, substitution and recycling. However, the pathways differ with respect to their level of ambition. Given the limited scope of the article, we will summarize the most important strategies and differences between the pathways and explain relevant general assumptions as well as specific assumptions with regard to substitution and recycling. For more details, see UBA (2019) and Dittrich et al. (2020a, 2020b, 2020c, 2020d, 2020e).

\section{Overall and structural changes with effects on resource demand}

All Green-Scenario assume a declining population in Germany by $-12 \%$ in 2050 compared to 2010 , based on official population projection by Destatis (2015). A declining population affects the whole economy, including the demand for food, energy, products and services as well as the demand for housing and overall infrastructure.

The demand for infrastructure furthermore depends on urban policies. In all Green scenarios, land sealing decreases, and thus the demand for new communal streets, water infrastructure as well as communal electricity and communication infrastructure declines. However, in GreenSupreme and GreenLife far less urban space is developed as people demand less living space $\left(41 \mathrm{~m}^{2}\right.$ per person) while in contrast, the built-up area is largest in GreenLate with high average living space demand $\left(53 \mathrm{~m}^{2}\right.$ per person) (Dittrich et al. 2020a, 2020b, 2020c, 2020d, 2020e, forthcoming).

Except for GreenSupreme, all scenarios assume a low overall economic growth of $0.7 \%$ p.a. In GreenSupreme, zero growth is assumed which implies that activity rates in several economic sectors are declining while at the same time other sectors are still innovative and expanding (Dittrich et al. 2020a, 2020b, 2020c, 2020d, 2020e, forthcoming). As a result of declining demand for infrastructure, housing, industrial and commercial buildings, the demand for construction services and construction materials declines in all scenarios, most distinctively in GreenSupreme. Likewise, the transformation of the energy system requires innovation and implies growth in the electricity, electronics and machinery sectors. In all scenarios, there is a shift towards services that are less resource-intensive compared to the extraction and industry.

Besides the population development, urban policies and economic growth, a fourth very important factor refer to the transition outside Germany. All pathways described by the green scenarios imply that European countries are transforming their economies towards a resource-efficient and greenhouse gas neutral Europe in the same way as Germany. Thus, all changes regarding substitution, recycling and efficiency described below are relevant in European countries as well. Hence, upstream flows of imports from European countries decline, accordingly. For example, if the energy system changes towards 
renewables in European countries, respective exports do not carry fossil backpacks anymore. Outside Europe, the world is changing as well. In the majority of Green pathways, the rest of the world is changing its energy system and its production processes with a lag of ten years and thus, reaching the full transformation in 2060. In GreenMe and GreenSupreme the rest of the world has already fully transformed its energy system by 2050 and produces its products and services as resource-efficient as it is assumed in Germany.

\section{Substitution}

In all green scenarios there are significant redirections of material flows. The dominant one, of course, is the substitution of fossil fuels by renewable energies: coal, currently used for electricity, is substituted by wind and solar power; petroleum and gas used for heat generation or mobility are substituted by renewably produced electricity and heat or by synthetic fuels. In all green scenarios, no fossil fuels are used in Germany in 2050 anymore - neither fossil fuels for energetic use nor fossil fuels as raw materials for plastics or paints. However, the scenarios differ in the speed and extent at which the substitution is implemented: while in GreenSupreme, both coal and petroleum are already substituted by renewables to a high degree in 2030, in GreenLate the changes start about ten years later.

In all green scenarios the building materials are changing: minerals are replaced by biotic materials. In Germany, there is a slight tendency toward wooden houses. This trend is perpetuated in GreenLate while it is intensified in GreenEe and GreenLife, following the sustainable pathway for building construction in Germany as explained in Deilmann et al. (2017). In GreenMe and GreenSupreme the substitution of minerals used in the housing sector by wooden materials is further strengthened: In 2050, the majority of new houses are built with wooden materials including insulation wherever feasible.

Further substitutions, particularly in GreenMe and GreenSupreme, include for example the use of aluminium instead of copper in electricity wires.

\section{Recycling}

In Germany, several materials such as paper, glass, plastics, construction minerals and metals are already being recycled. However, there is still potential to increase the amount of secondary materials used in the German economy. In all transformation pathways, the use of secondary materials increases. The increase in the recycling rate is only small in GreenLate but higher in GreenEe and GreenLife. Wherever feasible, further recycling efforts are implemented in GreenMe and GreenSupreme. In this context, the following paragraphs give some examples.

In 2010, iron scrap held a share of around $47 \%$ of input in steel production (UBA 2014). The share of secondary iron can be increased if steel production changes from blast furnace processes towards electric arc furnace processes. In 
GreenLate only $50 \%$ of iron scrap is used in steel production in 2050. All other transformation pathways assume a full change of steel production with a share of $67 \%$ of iron scrap in 2050. In GreenSupreme the scenario with the fastest overall transformation, steel production technology change starts already in 2025 and is accomplished in 2040.

Similar to iron, copper, aluminium, lead and zinc are recycled. In Germany copper scrap formed about $56 \%$ of copper production in 2010 . With respect to aluminium, lead and zinc, the secondary materials held an input share of 54\%, $73 \%$ and $39 \%$ in the respective metal production (UBA 2014). In the green scenarios, the shares of secondary materials increase due to improved collection, urban mining and technological changes. In GreenLate the share of secondary copper, aluminium, zinc and lead in metal production increase only up to $70 \%$ in 2050 . In the other green scenarios, however, the secondary metals hold a share of $90 \%$ in the respective non-iron metal production.

Likewise, recycling can further be improved with regard to other metals such as zinc, tin, silver or nickel. However, the data on the rates of secondary inputs in the respective metal production is less reliable due to a lack of data. Therefore, a general approach was used. In GreenEe and GreenLife the share of secondary metals increased by $10 \%$ until 2050 compared to the share in 2010. In GreenLate the increase is only 5\% while in GreenMe and Supreme the secondary share rises up by $25 \%$.

Further improvements in recycling comprise paper, plastics, wood, glasses and different construction minerals. With regard to some materials, the potential for improvement is low, for example, secondary paper already holds a high share of paper production. The paper industry produced around 23 million ton of paper in 2010, with an input of almost 16 million tons of secondary paper (UBA 2014). Thus, the potential for further increase is small and accounts only for $10 \%$ increase in 2050 compared to 2010 in all green scenarios. Recycling of other materials can be improved largely, for example for plastics. In GreenMe and GreenSupreme, 75\% of post-consumer plastics are recycled in 2050, compared to $47 \%$ in 2017.

\section{Further resource efficiency}

All pathways in the green scenarios include further efficiency measures with respect to energy and materials. Again, efforts differ between the pathways. The material efficient design of products, for example, lightweight electric cars, and material-efficient production technology, such as bifacial and thin cells, are used mostly in GreenMe and GreenSupreme. Material efficiency also increases due to improved processes and waste reduction in production and services. In the past, average material efficiency increased by $1 \%$ p.a. in Germany excluding structural effects of reunification (Dittrich et al. 2018). With regard to all sectors where no specific change was described, an average increase in material efficiency was assumed. In GreenLate it slows down to $0.9 \%$ p.a. which is in line with the European average while in GreenEe and 
GreenLife material efficiency increases to $1.1 \%$ p.a. and in GreenMe and GreenSupreme the rate raises to $1.2 \%$ p.a.

\section{The entive primary and secondary material consumption in the Green pathways}

All changes explained above, and further changes described in UBA (2019) and Dittrich et al. (2020a, 2020b, 2020c, 2020d, 2020e, forthcoming) result in a significant reduction of the consumption of primary raw materials ( $\mathrm{RMC}$; see Chapter 12, this volume). However, the entire material demand is higher due to secondary materials which are used as well. If the used secondary materials are expressed in raw material equivalents just like the used primary materials, the result reflects the amount of substituted primary materials. Furthermore, the share of secondary materials of in the entire material demand can be interpreted as the degree of circularity of an economy: $100 \%$ would be a fully circular economy without dissipative losses and no more demand of primary materials at all; $0 \%$ characterizes an economy that only uses primary materials without any recycling or reuse.

In addition to the raw material consumption, Figure 13.1 also shows the secondary materials expressed in tons of raw material equivalents. Secondary metals include iron, copper and aluminium. The other secondary materials comprise paper, wood, plastics and construction minerals such as recycled concrete, sand or gypsum. Secondary construction minerals are conservatively estimated without closed-loop recycling. Thus, the overall amount of used secondary material is a minimum estimation. While RMC decreases in all scenarios by at least $-56 \%$ (GreenLate) or even by $-70 \%$ (GreenSupreme) the volume of secondary materials in consumption increases in all scenarios. When following a conservative estimation, at least around 152 million tons (RME) of secondary materials were used in Germany in 2010. In 2050, at least 218 million tons of secondary materials are used in GreenLate and 260 million tons are used in GreenEe. GreenMe shows the highest amount of secondary materials with 270 million tons in 2050. In contrast, the amount is lowest in GreenSupreme with 206 million tons. The difference between GreenMe and GreenSupreme is interesting as in both pathways the shares of recycling materials are equal. Thus, the difference of 65 million tons is a consequence of the decrease in demand and particularly a decrease in the demand for construction minerals. With respect to construction minerals, transportation distances limit the use of secondary construction minerals although they are theoretically available.

The share of secondary materials in the entire material consumption increases in all Green pathways. While in GreenEe the degree of circularity is $10 \%$ in 2010 , it rises up to $32 \%$ in 2050 . The degree of circularity is highest in GreenMe (38\%) and lowest in GreenLate (27\%) with GreenSupreme (33\%) and GreenLife (31\%) in between.

Figure 13.1 also shows the substitutional effect of renewable energies expressing their contribution in tons of oil equivalents (RME). With growing 


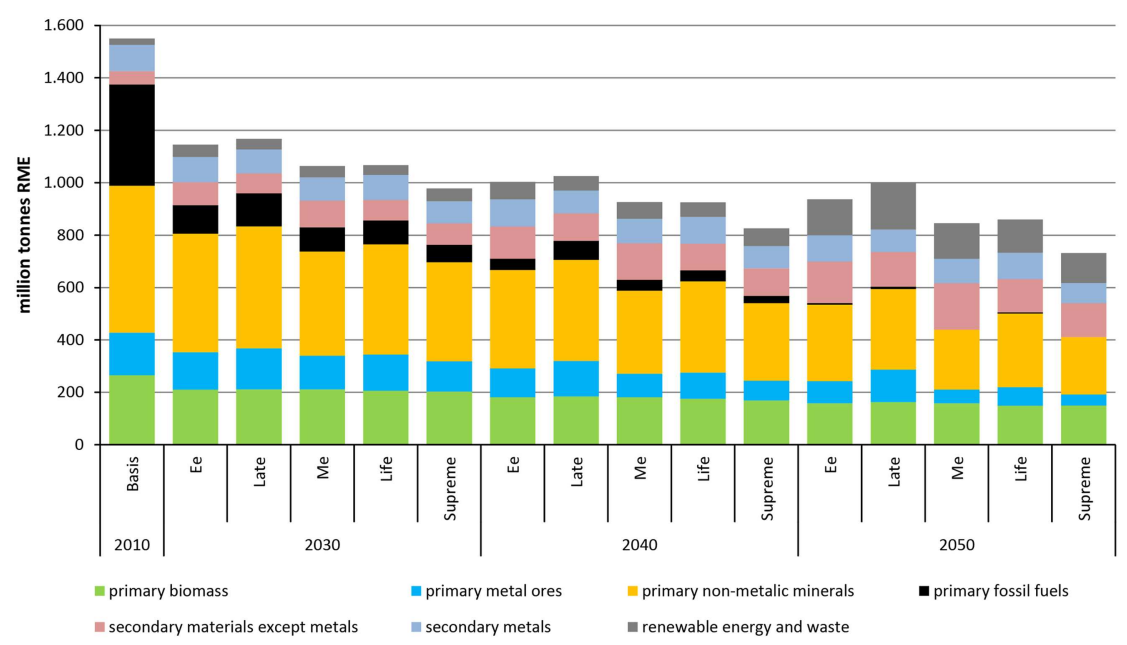

Figure 13.1 Primary and secondary raw material consumption in green scenarios. Source: own calculation in URMOD (2019).

energy efficiency and energy savings, the overall energy demand (provided by fossil fuels and renewables) decreases in all scenarios. However, the substitutional effect of renewables is highest in GreenLate in 2050 as overall energy demand is highest. In contrast, the effect is lowest in GreenSupreme due to the lowest energy demand in that pathway.

\section{Consumption of selected metals in the green pathways}

As explained in Chapter 12 of this volume, and presented in Figure 13.1, primary metal consumption declines at least by $24 \%$ in GreenLate and up to $74 \%$ in Supreme in 2050 compared to 2010. Including the secondary basic metals, there is still a decline of the entire metal consumption. Thereby, the decrease of primary and secondary metals in GreenLate is lowest with $-20 \%$ and highest in GreenSupreme with -5 4\% (GreenEe (-29\%), GreenLife $(-35 \%)$ and GreenMe $(-45 \%))$.

The use of iron is a suitable example to illustrate this trend. In GreenLate only small efforts are made in order to reduce overall iron demand and improve recycling. In 2010, 23 million tons of primary iron (here and in the following: iron content) and further 23 million tons of secondary iron have been consumed in Germany for products and investments. In GreenLate, the consumption of primary and secondary iron decreases to 33 million ton; thereof 16 million tons are primary iron and further 17 million tons are secondary iron. In GreenSupreme the pathway with the highest reduction of overall demand and high improvements of recycling, the consumption of iron is reduced to 24 million tons in 2050; 8 million tons primary and 16 million tons secondary iron, respectively. 
The transformation of the energy system implies not only a decreasing use of fossil fuels but also an increasing demand for metals for renewable energy installations. Generators of wind power plants, transformers in solar power, and batteries in electric cars are not operating without a considerable high amount and variety of metals. This trend was described already more than 10 years ago, e.g. by Elshkaki and van der Voet (2006) and further researched during the past decade, e.g. by Marscheider-Weidemann et al. (2016), IRP (2017b) or Rietveld et al. (2018). In the Green pathways the same trend can be observed: against the trend of declining metal consumption, technology and precious metals do not decrease but increase in 2030. In this respect, lithium can be adduced as a good example. Lithium is used in batteries in cars, lorries and busses. In GreenLate only few electric vehicles enter the market in 2030. Thus, demand for lithium for vehicle batteries is only 1,360 tons in 2030 while it is 2,500 in GreenLife where electric vehicles have a fast and wide market entry in upcoming and extensive car-sharing systems. In 2050, demand for lithium is highest in GreenLate with more than 26 thousand ton due to high numbers of vehicles. In contrast, demand is lowest in GreenSupreme with 9.6 thousand tons reflecting a smaller vehicle fleet combined with more efficient battery technology. However, compared to the (estimated) lithium production of 85 thousand tons in 2018 (USGS 2019), even a demand of 9.6 thousand tons would 'occupy" more than $11 \%$ of current global production. Thus, meeting the demand not only for Germany but also worldwide requires a significant increase in lithium extraction and the development of recycling structures for lithium batteries.

Besides lithium, demand for graphite, cobalt, silicon metal and further metals for new energy system technologies increase temporarily or continuously during the pathways. However, the demand for basic metals and for the majority of further metals decreases. If demand for steel decreases, demand for steel stabilisers such as chromium, nickel or manganese follows the same downward trend. Thus, the question arises whether the resulting primary metal consumption is still high or moderate. Therefore, the consumption of these raw materials was measured as a share of global production and compared to the share of the German population in world population. Figure 13.2 shows the metal consumption of Germany in 2030 and 2050 with respect to five different metals and differentiates all five transformation pathways as a share of current global production according to USGS.

With respect to iron in the GreenEe pathway, the consumption is $1.20 \%$ and $0.690 \%$ of current (2018) global production in 2030 and 2050, respectively. At the same time, in the ambitious pathway GreenSupreme the share is only $0.94 \%$ and $0.50 \%$ in the same years, respectively. Compared to the share of the German population in global population in 2050 (0.78\%, assuming medium global population development according to United Nations 2019) the consumption in GreenEe equals the share of population; it exceeds the "adequate" German share in GreenLate while it is clearly below in GreenMe, GreenLife and GreenSupreme. 


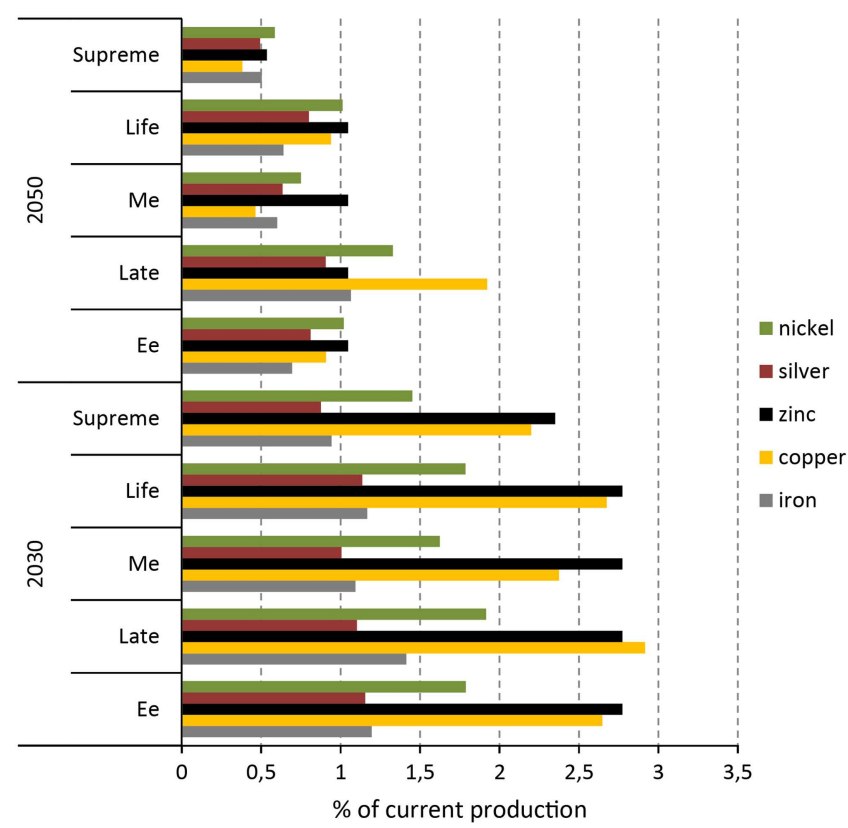

Figure 13.2 Metal consumption in Germany as a share of current global production.

Source: own calculation in URMOD and USGS (2019).

The other four selected metals copper, zinc, silver and nickel show a similar picture: consumption is still high in 2030, exceeding the population share in 2030 in nearly all pathways with respect to almost all metals. Thereby, demand for primary metals is highest in GreenLate and lowest in GreenSupreme. In 2050, in GreenEe and partly in GreenLife the "adequate" share is met, yet, exceeded in GreenLate and undercut in GreenMe and GreenSupreme. Particularly the copper demand is still high in GreenLate, reflecting the comparatively low ambition in recycling in this pathway in Germany as well as abroad. On the other hand, the low share in GreenMe and GreenSupreme is, among others, a result of efficient use within Germany but at the same time also a consequence of increasing global efficient use of primary copper incorporated in upstream flows of imports.

\section{Discussion and conclusion}

Currently, material consumption in Germany accounts for around 1.3 billion tons of primary raw materials. As extraction, procession, use, re-use and disposal is coercively linked to environmental impacts, a pathway towards to sustainable use of materials has to decrease material consumption significantly, in addition to a sustainable extraction, processing, use and recycling of materials. The closed 
link between material consumption and greenhouse gas emission has been shown and discussed in Chapter 12. In this contribution, we analysed the decrease of material demand and particularly metal demand in more detail.

Recycling, substitution and increasing efficiency are valuable measures in order to minimise material consumption. It is obvious that there is not only one strategy or measure; the combination of all measures and efforts leads as a result to a significant reduction of primary material consumption. However, the different ambitious levels of substitution, recycling and efficiency measures in the varying Green pathways result in different material consumption levels. The consequence of the comparatively low ambitious level in GreenLate is a relatively low decrease in material consumption and a low degree of circularity of the economy. Consequently, we have demonstrated that the resulting share of primary metal consumption of Germany in global production is still high. The fact that other countries also demand metals for their transformation or their economic development implies that global metal production has to increase to meet future global demand. This is linked to serious and increasing environmental consequences and impacts due to extraction, processing, use and disposal as described e.g. by van de Voet et al. (2018).

In contrast, ambitious technological changes, as shown in the GreenMe pathway, resulting in a significant decrease in overall material demand. Combining technological changes and life style changes - without loss of prosperity - make it possible to achieve a strong decline of primary material demand as illustrated in the GreenSupreme pathway. The resulting values of 5.7 tons per person (RMC) in GreenSupreme are clearly below the current global average of 11.98 tons (2015 according to IRP 2016) and already in the line with material consumption targets which were discussed for example, by Bringezu (2015). The degree of circularity was estimated conservatively in the presented approach. A degree of $30 \%$ and more is feasible with currently existing technologies. Thus, recycling efforts are significantly contributing to the reduction of primary material demand. This implies that logistics for collecting and separating have to be improved and technical facilities have to be (re)constructed. With respect to selected metals, this chapter has shown that the very ambitious pathways result in a significant decreasing demand for metals.

High ambitious levels lead to a decrease of demand for metals resulting in a low global share of demand. This is important as a fair global distribution is essential for global sustainability. A post-fossil, green Germany can be reached with a significant decrease in material consumption contributing to the mitigation of environmental impacts linked to extraction, processing, use and disposal of raw materials.

\section{List of abbreviations}

IRP International Resource Panel

RMC raw material consumption

RME raw material equivalent 


$\begin{array}{ll}\text { UBA } & \text { German Federal Environmental Agency } \\ \text { URMOD } & \text { Umweltökonomisches Rohstoffmodell (economic-environmental } \\ & \text { raw material model) } \\ \text { USGS } & \text { United States Geological Survey }\end{array}$

\section{References}

Bringezu, Stefan. (2015). Possible Target Corridor for Sustainable Use of Global Material. Resources 4(1), 25-54. doi:10.3390/resources4010025.

Deilmann, C., Reichenbach, J., Krauß, N., Gruhler, K. (2017). Materialströme im HochbauPotenziale für eine Kreislaufwirtschaft. Bonn/Dresden.

Destatis (2015). Bevölkerung Deutschlands bis 2060 - 13. koordinierte Bevölkerungsvorausbere chnung. Wiesbaden. www.destatis.de/DE/Publikationen/Thematisch/Bevoelkerung/ VorausberechnungBevoelkerung/BevoelkerungDeutschland2060Presse5124204099004. pdf?_blob=publicationFile.

Dittrich, M., Schoer, K., Kämper, C., Ludmann, S., Ewers, B., Giegrich, J., Sartorius, C., Hummen, T., Marscheider-Weidemann, F. (2018). Strukturelle und produktionstechnische Determinanten der Ressourceneffizienz: Untersuchung von Pfadabhängigkeiten, strukturellen Effekten und technischen Potenzialen auf die zukünftige Entwicklung der Rohstoffproduktivität (DeteRess). UBA-Texte, 29/2018. Dessau-Roßlau www.umweltbundesamt.de/sites/ default/files/medien/1410/publikationen/2018-04-11_texte_29-2018_deteress.pdf.

Dittrich, M., N. Gerhardt, K. Schoer, F. Dünnebeil, S. Becker, A. v. Oehsen, S. Koeppen, et al. (2020a). Transformationsprozess zum Treibhausgasneutralem und Ressourcenschonendem Deutschland - GreenEe. Climate Change 01/2020. Dessau-Roßlau.

Dittrich, M., N. Gerhardt, K. Schoer, F. Dünnebeil, S Becker, A. v. Oehsen, S. Koeppen, et al. (2020b). Transformationsprozess zum Treibhausgasneutralem und Ressourcenschonendem Deutschland - GreenLate. Climate Change 01/2020. Dessau-Roßlau.

Dittrich, M., N. Gerhardt, K. Schoer, F. Dünnebeil, S. Becker, A. v. Oehsen, S. Koeppen, et al. (2020c). Transformationsprozess zum Treibhausgasneutralem und Ressourcenschonendem Deutschland - GreenMe. Climate Change 01/2020. Dessau-Roßlau.

Dittrich, M., N. Gerhardt, K. Schoer, F. Dünnebeil, S. Becker, A. v. Oehsen, S. Koeppen, et al. (2020d). Transformationsprozess zum Treibhausgasneutralem und Ressourcenschonendem Deutschland - GreenSupreme. Climate Change 01/2020. Dessau-Roßlau.

Dittrich, M., N. Gerhardt, K. Schoer, F. Dünnebeil, S. Becker, A. v. Oehsen, S. Koeppen, et al. (2020e). Transformationsprozess zum Treibhausgasneutralem und Ressourcenschonendem Deutschland - GreenLife. Climate Change 01/2020. Dessau-Roßlau.

Elshkaki, A. and van der Voet, E. (2006). The consequences of the use of platinum in new technologies on its availability and on other metals cycles. In: Loeffe C. V. (ed.): Conservation and Recycling of Resources: A New Research. USA: Nova Publisher. 61-92.

IRP (2016). Global Material Flows and Resource Productivity. An Assessment Study of the UNEP International Resource Panel. Paris, United Nations Environment Programme.

IRP (2017a). Assessing Global Resource Use: A Systems Approach to Resource Efficiency and Pollution Reduction. A Report of the International Resource Panel. United Nations Environment Programme. Nairobi, Kenya.

IRP (2017b). Green Technology Choices: The Environmental and Resource Implications of LowCarbon Technologies. A report of the International Resource Panel. United Nations Environment Programme, Nairobi, Kenya. www.resourcepanel.org/reports/greentechnology-choices. 
IRP (2019). Global Resources Outlook 2019: Natural Resources for the Future We Want. A Report of the International Resource Panel. United Nations Environment Programme. Nairobi, Kenya. www.resourcepanel.org/reports/global-resources-outlook.

Marscheider-Weidemann, F., Langkau, S., Hummen, T., Erdmann, L., Tercero Espinoza, L. (2016). Rohstoffe für Zukunftstechnologien. DERA Rohstoffinformationen 28, Berlin. www.isi.fraunhofer.de/content/dam/isi/dokumente/ccn/2016/Studie_ Zukunftstechnologien-2016.pdf.

Rietveld, E., Boonman, H., van Harmelen, T., Hauck, M., Bastein, T. (2018). Global Energy Transition and Metal Demand - an Introduction and Circular Economy Perspectives. TNO.

UBA (2014). Treibhausgasneutrales Deutschland im Jahr 2050. www.umweltbundesamt. de/sites/default/files/medien/378/publikationen/07_2014_climate_change_dt.pdf.

UBA (2019). Transformationsprozess zum Treibhausgasneutralen und Ressourcenschonendem Deutschland. Climate Change 36/2019. Dessau-Rosslau. www.umweltbundesamt.de/rescue United Nations (2019). World Population Prospects 2019. Total Population - Both Sexes. https://population.un.org/wpp/Download/Standard/Population/.

USGS (2019). National Minerals Information Centre. www.usgs.gov/centers/nmic/.

Van de Voet, E., Van Oers, L., Verboon, M., Kupers, K. (2018). Environmental Implications of Future Demand Scenarios for Metals. Methodology and Application to the Case of Seven Major Metals. Journal of Industrial Ecology, 23(1), 141-154. 